\title{
Modelling Sociodemographic Factors That Affect Malaria Prevalence in Sussundenga, Mozambique.
}

\section{Joao Luis Ferrao ( $\nabla$ jferrao@isced.ac.mz )}

Instituto Superior de Ciencias de Educacao a Distancia https://orcid.org/0000-0002-3543-6459

\section{Dominique Earland}

University of Minnesota School of Public Health

\section{Anisio Novela}

Ministério da Saúde: Ministerio da Saude

\section{Roberto Mendes}

Universidade Catolica de Mocambique Faculdade de Economia e Gestao

\section{Marcos Ballat}

Universidade Catolica de Mocambique Faculdade de Engenharia

\section{Alberto Tungadza}

Universidade Católica de Moçambique Faculdade de Ciências de Saúde: Universidade Catolica de Mocambique Faculdade de Ciencias de Saude

\author{
Albino Bibe \\ Ministério da Saúde: Ministerio da Saude \\ Kelly Searle \\ University of Minnesota School of Public Health
}

\section{Research}

Keywords: sociodemographic, malaria, prevalence, Sussundenga

Posted Date: June 22nd, 2021

DOI: https://doi.org/10.21203/rs.3.rs-614728/v1

License: (c) (1) This work is licensed under a Creative Commons Attribution 4.0 International License.

Read Full License 
1 Modelling sociodemographic factors that affect malaria prevalence in Sussundenga, Mozambique.

3 João Luís Ferrão1*, Dominique Earland2, Anísio Novela3, Roberto Mendes4, Marcos

${ }^{1}$ Instituto Superior de Ciências e Educação a Distância, Moçambique; 2School of Public Health. University of Minnesota 3Direccao Distrital de Saúde de Sussundenga,

8 4Roberto Mendes, Centro de GIS, Faculdade de Economia, Universidade Católica de Moçambique 7Escola Secundaria de Sussundenga albino.bibe@gmail.com; *Corresponding author: João Luís Ferrão - jferrao@isced.ac.mz, 


\section{Abstract}

\section{Background}

17

Malaria is still one of the leading causes of mortality and morbidity in Mozambique with little progress in malaria control over the past 20 years. Sussundenga is one of most affected areas. Malaria transmission has a strong association with environmental and socio-demographic factors. The knowledge of sociodemographic factors that affects malaria, may be used to improve the strategic planning for its control and, such studies do not exist in Sussundenga. Hence, the objective of this study is to model the relationship between malaria and sociodemographic factors in Sussundenga, Mozambique.

\section{Methods}

Houses in the study area were digitalized and enumerated using GoogleEarth ProTM. Hundred houses were randomly selected to conduct a community survey of $\mathrm{P}$. falciparum parasite prevalence using rapid diagnostic test (RDT). During the survey, a questionnaire was conducted to assess the socio-demographic factors of the participants. Descriptive statistics were analyzed and backward stepwise logistic regression was performed establishing a relationship between positive cases and the factors. The analysis was carried out using SPSS version 20 package.

\section{Results}

The overall P. falciparum prevalence was $31.6 \%$. Half of the malaria positive cases occurred in age group 5 to 14 years. Previous malaria treatment, population density and age group were significant predictors for the model. The model explained $13.5 \%$ of the variance in malaria positive cases and sensitivity of the final model was $73.3 \%$. 


\section{Conclusion}

38 In this area the highest burden of $P$. falciparum infection was among those $t 5-14$ years 39 old. Malaria infection was related to socio-demographic factors. Targeting malaria control 40 at community level can contributed better than waiting for cases at health centers. These

41 finding can be used to guide more effective interventions in this region.

\section{Trial registration}

43 Review Board (IRB) at the University of Minnesota STUDY00007184

44 CNBS [IRB00002657]

45 Keywords: sociodemographic; malaria; prevalence; Sussundenga 
Modelling sociodemographic factors that affect malaria prevalence in Sussundenga, Mozambique.

\section{Background}

Malaria is a serious and sometimes fatal disease caused by a Plasmodium parasite that commonly infects Anopheles mosquitos which feeds on humans. Although malaria can be a deadly disease, infection and death can be prevented ${ }^{1}$. Almost half of the world's population lives in areas at risk of malaria transmission. Six countries account for more than half of all malaria cases worldwide and Mozambique is among them².

In Mozambique, a country in sub-Saharan Africa, with a population of over 30 million inhabitants, malaria is one of the leading causes of mortality and morbidity. In 2018, Mozambique recorded the third largest number of malaria cases in the world, that is, $5 \%$ of all cases ${ }^{3}$.

The country has made little progress in malaria control. Indoor residual spraying (IRS), insecticide treated bed nets (ITNs), and parasitological diagnosis in health facilities using rapid diagnostic test (RDTs) with effective artemisinin combination therapy (ACT) are the malaria intervention currently being used. The entire country uses RDTs with ACT as the standard of care in public health facilities and ITNs are only available at antenatal clinics, indicated for pregnant women and children under $5^{4}$.

Manica Province in central Mozambique has the second highest malaria incidence in the country. In the first quarter of 2020, recorded 1,039,283 cases with an incidence of 371 per 1000 inhabitants ${ }^{5}$. Sussundenga village, in Manica Province is one of most affected areas, with 31,397 malaria cases reported in 2019.

Malaria risk, disease severity, and clinical outcome depend on environmental, sociodemographic, economic, and behavioral factors ${ }^{6,7,8,9}$. A study in Chimoio, the Provincial 
72 capital of Manica, close to Sussundenga Village, modelled the influence of climate on

73 malaria occurrence and indicated that selected environmental characteristics accounted

74 for malaria incidence by $72.5 \%$ implying that non-environmental factors such as

75 sociodemographic, economic, cultural and behavioral traits would account for the res ${ }^{10}$.

76 While Mozambique has one of the highest incidences and prevalence of malaria in the

77 region and, it accounts for nearly half of childhood deaths, little is known about the

78 epidemiology to inform appropriate and effective interventions. This is one of two major

79 barriers to expanding control measures in the country with the other being limited funding.

80 In the country, malaria transmission occurs all year round and, the knowledge of

81 sociodemographic factors that affect malaria is crucial for informing the implementation

82 of the most appropriate and effective malaria interventions to achieve control. In

83 Sussundenga no studies are known in this field. Therefore, the objective of this study was

84 to model the relationship between malaria and sociodemographic factors in Sussundenga

85 Rural Municipality.

86 2. Methods

$87 \quad 2.1$ Study area.

88 The village of Sussundenga is a rural, agrarian community $40 \mathrm{Km}$ from the Zimbabwe 89 border, and is 40 kilometers from the provincial capital of Chimoio (Figure 1).

90 Sussundenga has an estimated population of 31,429 inhabitants, $47 \%$ males and $53 \%$

91 females. The age distribution is: $19.5 \%$ from 0 to 4 years old, $29.9 \%$ from 5 to 14 -year-

92 old, $20.5 \%$ from 15 to 24 years old and $30.1 \%$ with over 24 years old ${ }^{11}$. 
93 The climate is tropical with an average annual precipitation of $1,200 \mathrm{~mm}$. The rainy 94 season occurs from November to April. The average minimum temperature is $6.3^{\circ} \mathrm{C}$ in

95 the month of July and the average maximum temperature is $38.9^{\circ} \mathrm{C}$ in the month of 96 January and the annual average is $21.2^{\circ} \mathrm{C}^{12}$. The village is divided administratively in 17 97 residential areas called "Bairros".

\subsection{Data collection}

99 GoogleEarth Pro ${ }^{\mathrm{TM}}$ satellite imagery was used to digitize and enumerate all household 100 structures in the village of Sussundenga. A random sampling of 125 households was 101 taken; 100 households for enrollment in the study and 25 households as backup for 102 refusals and errors in the digitizing process (misclassified non-household structures).

103 Coordinates of the households were extracted using a GPS device and maps of the 104 selected households to conduct study visits. The study involved two visits to the selected 105 households. The first was a notification visit where the study team introduced themselves 106 to the head of the household and explained the objectives and procedures of the study. 107 It is customary for the head of household to provide permission to the study team before 108 any activities take place at the household involving other household members. Once the 109 head of household gave permission, the study team conducted a household census with 110 the head of household and begin the process of individual informed consent with the

111 household residents, for all adult (18+ years) residents and parental permission and 112 assent from minors.

113 After obtaining consent from the household residents, the study team informed 114 participants when they will return the following day to conduct the study activities. The 115 only eligibility requirement was that the residents live in household full time. Data 
116 collectors verbally administered a questionnaire to collect the basic demographics. The

117 field study was carried out from December 2019 to January 2020.

118 The study nurse collected current malaria specific symptoms by self-report and will took 119 participant's temperature using a digital thermometer (Mebaline). They then collected a 120 finger prick blood sample to administer a Rapid Diagnostic Test (RDT), RightSign Biotest 121 R (Biotest, Hangzhou Biotest Biotech Co, China). According to the 122 manufacture, this test captures the HRP2 antigen on the strip and its 123 sensitivity is $>99.0 \%$. The results were recorded and, in the event, that a participant 124 was positive for malaria, the study nurse referred them to the Sussundenga rural health 125 center (RHC) for diagnosis confirmation and treatment. The questionnaire was conducted 126 using tablet computers with the REDCap (Research Electronic Data Capture, USA) a 127 secure, web-based data capture tool. Data was stored in a secure REDCap server hosted 128 by the University of Minnesota.

\subsection{Data Analysis}

130 This study was a cross-sectional community-based survey. The analyses were conducted 131 on datasets downloaded from REDCap to excel spread sheet (additional file 1). As 132 variables, a binary variable as the dependent variable malaria infection, that is whether 133 malaria was present (positive) to RDT or absent (negative) was used.

134 The explanatory variables analyzed were the following sociodemographic factors: age, if 135 the person was an adult or child, age category, sex, history of malaria treatment, paid 136 employment, cell phone ownership, education level, population density, location (Bairro), 137 household category and household size. 
138 The malaria prevalence, was calculated dividing positive cases of malaria by the study 139 population tested at the time multiplied by $100^{13}$.

141 Chi-square for proportion of age group and sex was tested. To establish the relationship 142 between malaria prevalence and socio-demographic factors, logistic backward stepwise 143 logistic regression was used with the following model:

$$
X_{i}: g(P i)=\beta_{0}+\beta_{1} X_{1}+\beta_{2} X_{2}+\ldots B i x_{i}
$$

145 Where:

$146 G\left(P_{i}\right)=$ link function

$147 P_{i}=$ likelihood of response for the - ith factor

$148 B_{0}=$ intercept

$149 \quad B_{1}=$ coefficient

$150 \quad x_{1}=$ independent variable.

151 This method starts with a full (saturated) model and at each step gradually eliminates 152 variables that do not contribute for the model to find a reduced model that best explains 153 the data. This method is useful since, it reduces the number of predictors, reducing 154 multicollinearity and resolves overfitting ${ }^{14}$.

155 To evaluate potential confounders and, effect modifiers between the final model variables, 156 Hosmer -Lemeshow (1989) test was performed ${ }^{15}$. To build the final model, the 157 independent variables $p<0.05$ were included. Outcomes such as Scores statistic's, 158 regression coefficient's, significance levels of variable coefficients and, overall 159 classification accuracy were performed 
160 The model sensitivity (conditional probability of a positive test given that the patient has

161 malaria) of the final model measures the proportion of positive that were correctly

162 identified and, was calculated as ${ }^{16}$ :

$$
\text { Sensitivity }(\%)=\frac{\text { Number of true malaria positive }}{\text { Number of true malaria positive }+ \text { Number of false malaria negative })} \times 100(3.1)
$$

164 The model specificity (conditional probability of a negative test given that the patient is 165 well) of the final model measures the proportion of negative case correctly identified and 166 was calculated as ${ }^{16}$ : people who tested positive do or do not actually have malaria was calculated as ${ }^{16}$ :

$$
P P V(\%)=\frac{\text { Number of true malaria positive }}{\text { Number of true malaria positive }+ \text { Number of false malaria positive) }} \times 100 \text { (3.3) }
$$

171 Negative Predicted Value (NPV) that is, the conditional probability that an individual with

172 a test indicative of No malaria is actually disease free, was calculated as $^{16}$ :

$$
N P V(\%)=\frac{\text { Number of true malaria negatives }}{\text { Number of true malaria negatives }+ \text { Number of false malaria negative) }} \times 100 \text { (3.4) }
$$

All tests were carried out using SPSS IBM version 20.

This study is part of the Malaria Risk, Prevention, and Health Seeking Behaviors in

177 Sussundenga, Mozambique Project. All participants, or the guardians provided informed written assent and consent prior to participation. Ethical review and approval for the study was completed by the Institutional Review Board (IRB) at the University of Minnesota 


\section{Results}

\subsection{Malaria prevalence, sex, age and, age group and education level of} participants.

From 125 selected households 100 were visited Figure 2 presents the positive and negative cases per visited site. Of the 358 participants tested and, interviewed 108 (31.6 \%) tested positive for malaria. There was an equal distribution of the enrolled participants among sex, $55 \%$ were female and $45 \%$ males, Chi-square $=0.081, P=0.8872, D F=1$. No difference was found between female and male positive cases, 53 and $47 \%$ respectively, Chi-square $=0.180, \mathrm{P}=07772, \mathrm{DF}=1$.

The age of participants varied from 1 to 80 years old, with a median of 17 years and an average of 21 standard deviation (SD), 16.2 years old. For the participants' education level $(n=302), 35.1 \%$ had no education or less than primary (5 grades), $47.4 \%$ had primary or basic school (grades 5 to 10 ) and $17.5 \%$ had secondary and higher education.

\subsection{Malaria prevalence by age category}

Figure 3 presents the malaria positivity results for age categories. Half of the malaria positive cases occurred among those 5 to 14 years age category. This category comprises has $32.7 \%$ of the Sussundenga population according to the National Institute of statistics (INE). Age category over 24 years presented $17.6 \%$ the malaria This age category comprises $30.4 \%$ of the Sussundenga population according to INE. There was a statistically significant difference in positive malaria cases among groups, Chi-square $=$ 17.527, $\mathrm{P}=0.0075, \mathrm{Df}=6$.

\subsection{Association between malaria infection and sociodemographic factors.}


The backward stepwise regression selection of predictors into the binary logistic model produced a series of model and, in this study, we only present the relevant, initial models and other outputs can be found in appendix 1.

207 Table 1 presents the backward stepwise (Wald) model summary and the Nagelkeke's $\mathrm{R}^{2}$ in final step is 0.135 suggesting that malaria presence explained variation in the dependent variable in this model is approximately $13.5 \%$.

Table 1. Backward stepwise model summary

\begin{tabular}{|l|r|r|r|}
\hline Step & -2 Log likelihood & $\begin{array}{c}\text { Cox \& Snell R } \\
\text { Square }\end{array}$ & $\begin{array}{c}\text { Nagelkerke R } \\
\text { Square }\end{array}$ \\
\hline 1 & $408.482^{\mathrm{a}}$ & .109 & .151 \\
\hline 9 & $413.304^{\mathrm{b}}$ & .096 & .135 \\
\hline $\begin{array}{l}\text { a. Estimation terminated at iteration number 5 because parameter estimates changed by } \\
\text { less than .001. }\end{array}$ \\
$\begin{array}{l}\text { b. Estimation terminated at iteration number 4 because parameter estimates changed by } \\
\text { less than .001. }\end{array}$
\end{tabular}

Table 2. Hosmer and Lemeshow Test

\begin{tabular}{|l|r|r|c|}
\hline Step & Chi-square & Df & Sig. \\
\hline 1 & 8.558 & 8 & .381 \\
\hline 9 & 5.990 & 8 & .648 \\
\hline
\end{tabular}

Table 3 presents the classification table of the final model, that is, the model capability to predict malaria positive cases, indicating a model accuracy of $71.6 \%$. The sensitivity of the final model in classifying malaria positive cases is $73.3 \%$ and specificity of the final model to classify malaria negative cases is $93.3 \%$. The positive predictive value is $66 \%$ and, the Negative Predictive Value is $72.5 \%$ meaning that, the final model is able to predict $66 \%$ of malaria positive tests and, $72.5 \%$ negative malaria tests.

Table 3. Final backward stepwise (Wald) model classification table

\begin{tabular}{|c|c|c|c|c|c|}
\hline \multirow[b]{3}{*}{ Observed } & & & \multicolumn{3}{|c|}{ Predicted } \\
\hline & & & \multicolumn{2}{|c|}{ Malaria results } & \multirow{2}{*}{$\begin{array}{c}\text { Percentage } \\
\text { Correct }\end{array}$} \\
\hline & & & Negative & Positive & \\
\hline \multirow[t]{3}{*}{ Step 1} & \multirow[t]{2}{*}{ Malaria result } & Negative & 218 & 22 & 90.8 \\
\hline & & Positive & 77 & 39 & 33.6 \\
\hline & \multicolumn{2}{|c|}{ Overall Percentage } & & & 72.2 \\
\hline
\end{tabular}




\begin{tabular}{|l|l|l|r|r|r|}
\multirow{3}{*}{ Step 9} & Malaria result & Negative & 224 & 16 & 93.3 \\
\cline { 2 - 6 } & & Positive & 85 & 31 & 26.7 \\
\cline { 2 - 6 } & Overall Percentage & & & 71.6 \\
\hline a. The cut value is .500
\end{tabular}

221 Table 4 presents the Wald's test of significance and the odds ratio predictors variables in

222 the final model. From the results, pervious malaria treatment $(p=0.15)$, population density

$223(p=0.05)$ and, age group $(p=0.00)$ were significant predictors while, household category

224 did not add significantly to the model. The table indicates that the age category 0 to 4 225 years old as almost three times chance to test positive for malaria (OR 2.829, $95 \% \mathrm{Cl}$ $2261.153-6.944)$, 3.6 times (OR 3.61, $95 \% \mathrm{Cl} 1.952-6.755)$ for age group 5 to 14 years 227 and, 1.6 times (OR 1.603, $95 \%$ Cl $0.824-3.117)$.

Table 4. Final model Wald's of significance and odds ratio of predictor variables

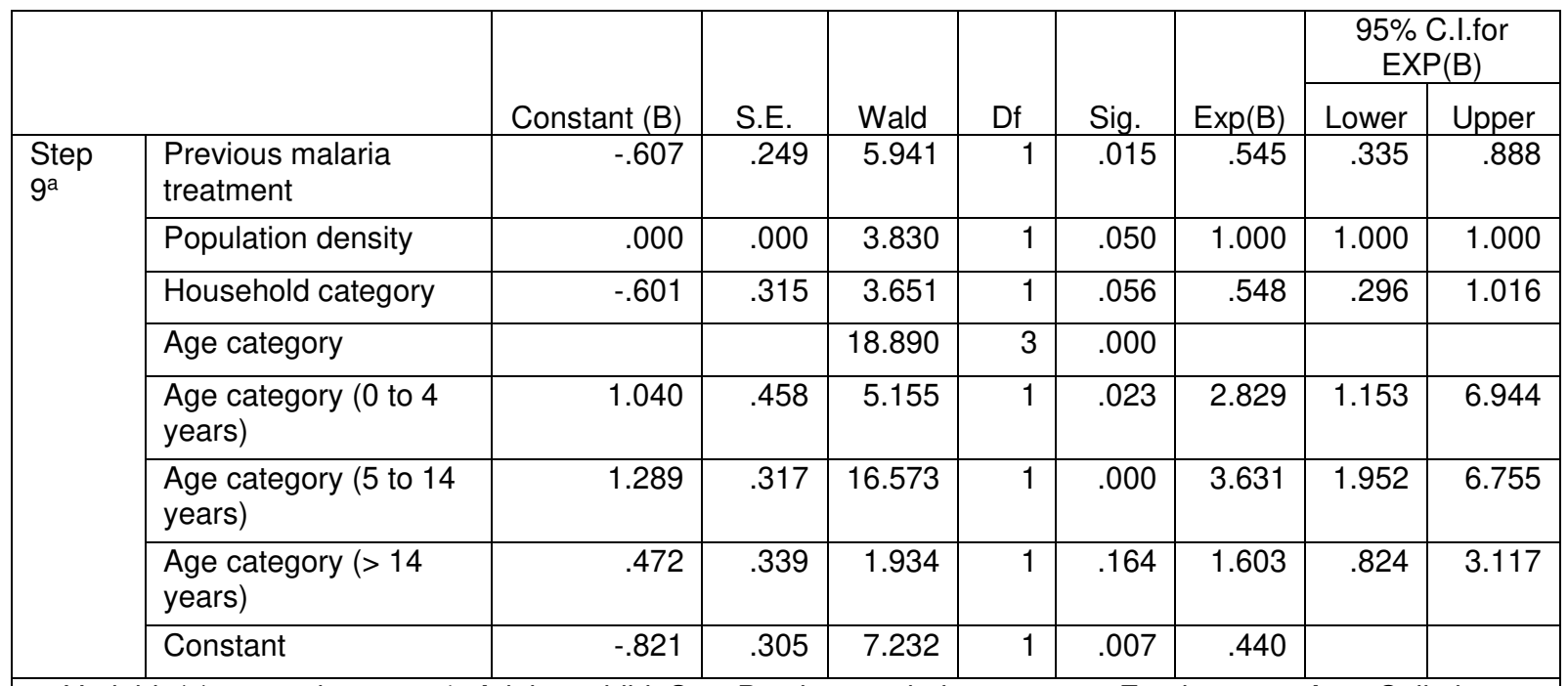

a. Variable(s) entered on step 1: Adult or child, Sex, Previous malaria treatment, Employment, Age, Cell phone, Education, Population density, Household size, HH category, Age category, Location

$229 B=$ regression coefficients, S.E = standard errors, Wald $=$ Wald test, Df $=$ degrees of freedom, Sig. $=$ Wald's

231 The built model is:

\section{Discussion}


235 In this study, malaria prevalence was $31.6 \%$ for Sussundenga Village, much higher than 236 the prevalence recorded in Chimoio city ${ }^{17}$ of $20.1 \%$. In the neighboring Zimbabwe, malaria 237 prevalence was $19.5 \%$ in Mutare and $50.9 \%$ in Mutasa districts in $2016^{18}$. In southern 238 Zambia a study in 2020, reported parasite prevalence between 0.7 and $1.8 \%^{19}$ and, $34 \%$ 239 in Malawi in $2016^{20}$.

240 No difference was found between sex in this study. Similar results were reported in 241 Chimoio, Mozambique in 2018 ${ }^{17}$, in Malawi in $2020^{21}$ and in Zimbabwe 22 in 2021.

242 This study recorded half malaria prevalence in the 5 to 14 years age category and, OR of 243 3.61. In Ghana it was recorded $43.3 \%$ and, in Rwanda the odds of infection by malaria 244 were reported to be 1.817 times for this age category ${ }^{23,} 24$. Studies in Kenya indicated that 245 highest malaria prevalence occurs in children between ages of 11 to 14 and, children 246 from 5 to 18 years as the most at-risk age category ${ }^{25,26}$. Contrarily, in Chimoio, 247 Mozambique it was reported $52 \%$ of malaria cases in children under five ${ }^{17}$ and, the 248 discrepancy may due to the fact that the present study was carried out at community level 249 while, the Chimoio study was carried out from health center data.

250 This study suggests that recent diagnosis and treatment for malaria infection reduces the 251 odds of subsequent infection approximately by $54.5 \%$. Similar results were reported in 252 Mozambique, Ghana, Comoros, Kenya, Indonesia and India ${ }^{27,28, ~ 29, ~ 30, ~ 31, ~ 32, ~ 33 . ~ T h i s ~}$ 253 reduction in odds is likely due to prophylactic effect of ACT. It provides protection usually 2542 weeks to 1 month after completion. After repeated infections, the individual develops a 255 certain degree of immunity. Also, when re-infected, patients present a mild form of the 256 diseases without symptoms. Natural active immunity is established after ten or more $P$. 257 falciparum infections, which can be sufficient to suppress symptoms and clinical signs ${ }^{34}$. 
258 Different results were reported in Angola where women who had a previous malaria 259 infection during pregnancy also had a higher risk to contract malaria ${ }^{35}$. This is likely 260 because pregnant women may take SP rather than ACT.

261 In this study population density was found as a significant predictor for an individual to 262 test positive for malaria. Similar results were reported in Chimoio ${ }^{17}$ in 2016 , in a study in 26314 endemic African countries ${ }^{36}$ in 2017 and in Ethiopia ${ }^{37}$ in 2015.

264 The variables age, if the person was an adult or child, sex, paid employment, cell phone 265 ownership, education level, location (Bairro) and household size were removed from the 266 model due to redundancy and for not adding significance to the model.

267 Age category is a good proxy for age group and, household size for household category. 268 Paid employment ant cell phone ownership variables were included in this study, as rural 269 wealth indicators and, were not found significant predators contrary to study in 270 Mozambique that indicated that, Children from higher income families (58\%) tend to be 271 at lower risk for malaria compared to children from lower income families $(43 \%)^{38}$ and, in 272 Sub-Saharan Africa ${ }^{39}$ that, find malaria prevalence increases with decrease in income in 2732018.

274 Education level was not finding significant predictor in this study. Similar results were 275 reported in Malawi in $2018^{40}$, Indonesia and India ${ }^{32,33}$. Different results were reported in 276 Mozambique ${ }^{38}$ in 2011, in Ghana in 2014 and in Sub-Saharan Africa ${ }^{39}$ in 2018.

277 In this study it is suggested that approximately $13.5 \%$ of the variation in malaria infection 278 can be attributed to sociodemographic and economic traits. Previous study modelled the 279 influence of climate on malaria occurrence in Chimoio and indicated that environmental 280 traits accounted for malaria occurrence by $72.5 \%$, implying that non-environmental 
281 factors such as sociodemographic, economic, cultural and behavioral traits could partially

282 account for the remaining percentage, consistent with this result.

283 The Model using social, economic, and demographic variables capability to predict 284 malaria positive cases (model accuracy), was $72.3 \%$ in this study. A logistic regression 285 model analyzing hematological parameter and age in Ghana reported $77.4 \%^{23}$. The 286 sensitivity of the final model in classifying malaria positive cases was $73.3 \%$ and the final 287 model was able to predict $66 \%$ (positive predictive value) meaning that the model is very 288 effective in predicting malaria infection using socio demographic characteristics. In Iran a 289 model predicting malaria re-introduction reported $81.8 \%$ positive predictive value [40] and $52.72 \%$ in Ghana in a model analyzing hematological parameter and age ${ }^{26}$.

\section{Limitations of the study}

292 Data collection for this study was conducted in December and January during the rainy 293 and wet season which is also the peak malaria transmission season. Because of this, it 294 is likely that we detected a large number of infections and results reflect this season and 295 my not be representative of malaria dynamics in the dry season. The RightSign Biotest ${ }^{R}$ 296 test detects the histidine rich protein 2 antigen of the Plasmodim falciparum parasite 297 which can last over a month in the blood among patients recently treated with malaria.

\section{Conclusion}

299 This study evaluated the sociodemographic factors that affect malaria prevalence in 300 Sussundenga Village, Mozambique. Recent diagnosis and treatment, population density 301 age category was found to be significant predators. The model accuracy was $72.3 \%$ and 302 implying that the model is robust. Targeting malaria control at the community level can 303 contribute to decreased transmission that may be more impactful than passive case 
detection and treatment alone. This model indicates that $13.5 \%$ of malaria cases can be attributed to sociodemographic factors while previous studied indicated that environmental conditions are attributed to approximately $73 \%$ of malaria cases. Further studies are needed specially in dry season and in other areas of the district to fully understand the malaria transmission dynamics in this region and inform efficient control measures.

\section{Acknowledgments}

We would like to thank the Provincial and district directorates of health to grant permission to carry out this study specially the Dr. Firmino Jaqueta, Dr. Serafina Benesse, Dr. Filipe Murgorgo and Mrs. Elsa Trabuco. We also thank Mr. Gabriel Viegas for figures editing.

\section{References}

1. Centers for Disease Control and Prevention. About Malaria- Biology. Centers for Disease Control and Prevention. 2012. http://www.cdc.gov/malaria/about/biology. Accessed July 14, 2020.

2. World Health Organization. The World malaria report 2018. WHO. 2018. https://apps.who.int/iris/bitstream/handle/10665/275867/9789241565653-eng.pdf Accessed July 27, 2020.

3. World Health Organization. Making strides against malaria in Mozambique: Control, prevention and treatment in action. WHO. 2020. https://www.who.int/malaria/making-strides-against-malaria-in-mozambique. Accessed July 14, 2020.

4. World Health Organization. Mozambique 2018. WHO. Published 2018. https://www.who.int/malaria/publications/countryprofiles/profile_moz_en.pdf?ua=1 . Accessed July 14, 2020.

5. DPS. Relatório Do Primeiro Semestre Do Ano 2020.; 2020. Governo da Provincia de Manica.

6. Chuang, TW., Soble, A., Ntshalintshali, N. et al. Assessment of climate-driven variations in malaria incidence in Swaziland: toward malaria elimination. Malar J 16, 232 (2017). https://doi.org/10.1186/s12936-017-1874- 
7. Manh BH, Clements ACA, Thieu NQ, et al. Social and environmental determinants of malaria in space and time in Viet Nam. Int $\mathrm{J}$ Paras. 2011;41doi:10.1016/j.ijpara.2010.08.005

8. Instituto Nacional de Estatística. Inquérito Demográfico e de Saúde. INE. Published 2011. http://www.ine.gov.mz/operacoesestatisticas/inqueritos/inquerito-demografico-e-de-saude/mocambique-inqueritodemografico-e-de-saude-2011. Accessed July 14, 2020.

9. Edwin P, Msengwa A. Prevalence and socio-demographic factors associated with malaria infection among children under five years in Tanzania. Jour Pub Helt Epid. 2018. DOI: 10.5897/JPHE2018.1055

10. Ferrão JL, Mendes JM, Painho M. Modelling the influence of climate on malaria occurrence in Chimoio Municipality, Mozambique. Parasites and Vectors. 2017;10. doi:10.1186/s13071-017-2205-6

11. INE. Projecções Anuais da População Total, Urbana e Rural, dos Distritos, 20072040 (volumes correspondestes às 11 províncias). INE. 2010. http://www.ine.gov.mz/estatisticas/estatisticas-demograficas-e-indicadoressociais/populacao/projeccoes-da-populacao

12. Ministério da Administração Estatal. Perfil Do Distrito De Sussundenga. INE. Published 2005. Accessed July 12, 2020. http://www.ine.gov.mz/estatisticas/estatisticas-territoriasdistritais/manica/2011/distrito-de-sussundenga.pdf/view

13. Center for Disease Control. Principles of Epidemiology in Public Health Practice, Third Edition: An Introduction. Third. (CDC, ed.). CDC; 2006. https://www.cdc.gov/csels/dsepd/ss1978/SS1978.pdf

14. de Oliveira EC, dos Santos ES, Zeilhofer P, Souza-Santos R A-SM. Geographic information systems and logistic regression for high-resolution malaria risk mapping in a rural settlement of the southern Brazilian Amazon. Malar J. 2013;12. doi:10.1186/1475-2875-12-420.

15. Laerd Statistics. Binomial Logistic Regression using SPSS Statistics. https://statistics.laerd.com/spss-tutorials/binomial-logistic-regression-using-spssstatistics.php.

16. Trevethan R. Sensitivity, Specificity, and Predictive Values: Foundations, Pliabilities, and Pitfalls in Research and Practice Front. Public Health. 2017. doi.org/10.3389/fpubh.2017.00307

17. Ferrão JL, Mendes JM, Painho M, João SZ. Spatio-temporal variation and sociodemographic characters of malaria in Chimoio municipality, Mozambique. Malar J. 2016;15. doi:10.1186/s12936-016-1371-x

18. Sande S, Zimba M, Chinwada P, Masendu HT, Mberikunshe J, Makuwaza A. A review of new challenges and prospects for malaria elimination in Mutare and 


\section{Ndong, I.C., Okyere, D., Enos, J.Y. et al. Prevalence of asymptomatic malaria} parasitaemia following mass testing and treatment in Pakro sub-district of Ghana. BMC Public Health 19, 1622 (2019). https://doi.org 
30. Artadji A. Recul et persistance du paludisme en Union des Comores : une approche géographique pour déterminer l'importance des facteurs environnementaux et sociaux dans son maintien. Géographie Univ la Réunion. Published online 2019. doi:2019LARE0003

31. Ernst KC, Lindblade KA, Koech D, et al. Environmental, socio-demographic and behavioural determinants of malaria risk in the western Kenyan highlands: A case-control study. Trop Med Int Heal. 2009;14(10):1258-1265. doi:10.1111/j.1365-3156.2009.02370.x

.32. Hasyim H, Dale P, Groneberg DA, Kuch U, Müller R. Social determinants of malaria in an endemic area of Indonesia. Malar J. 2019;18(1):134. doi:10.1186/s12936019-2760-8

33. Ranjbar M, Shoghli A, Kolifarhood G, Tabatabaei SM, Amlashi M, Mohammadi M. Predicting factors for malaria re-introduction: An applied model in an elimination setting to prevent malaria outbreaks. Malar J. 2016;15(1):138. doi:10.1186/s12936-016-1192-y.

34. Leide Daiana Mioto, Ligia Carla Faccin Galhardi MKA. Aspectos parasitológicos e imunológicos da malária. Biosaúde. 2012;14(1):42-55. http://www.uel.br/revistas/uel/index.php/biosaude/article/download/24324/17894

35. Campos PA, Valente B, Campos RB, et al. Plasmodium falciparum infection in pregnant women attending antenatal care in Luanda, Angola. Rev Soc Bras Med Trop. 2012;45(3):369-374. doi:10.1590/s0037-86822012000300017

36. AS, Bouma MJ, SantosVega M, Yeshiwondim AK, Rothman DS, Yadeta D, Sutton PC, Pascual M. 2015 Temperature and population density determine reservoir regions of seasonal persistence in highland malaria. Proc. R. Soc. B 282: 20151383

37. The impact of urbanization and population density on childhood Plasmodium falciparum parasite prevalence rates in Africa Caroline W. Kabaria1,2*, Marius Gilbert3,4, Abdisalan M. Noor2,5, Robert W. Snow2,5 and Catherine Linard3,6

38. Instituto Nacional de Estatistica. Inqueriro Sociodemografico e de Saude 2011. INE. 2012. https://dhsprogram.com/pubs/pdf/PR14/PR14.pdf

39. Degarege A, Fennie K, Degarege D, Chennupati S, Madhivanan P (2019) Improving socioeconomic status may reduce the burden of malaria in sub-Saharan Africa: A systematic review and meta-analysis. PLoS ONE 14(1): e0211205. https://doi.org/10.1371

40. Kabaghe, A.N., Chipeta, M.G., Gowelo, S.et al Fine-scale spatial and temporal variation of clinical malaria incidence and associated factors in children in rural Malawi: a longitudinal study. Parasites Vectors 11, 129 (2018). https://doi.org/10.1186/s13071-018-2730-y 
$451 \quad$ Figure Legends

452 Figure 1. Study area. A. Map of Mozambique, Manica Province and Sussundenga District:

453 adapted from CENACARTA, Public, https://www.mozgis.gov.mz. B. High resolution imagery of 454 Sussundenga village from Google Earth $\operatorname{Pro}^{\mathrm{TM}}$ C. Sampled site in Sussundenga Village:

455 adapted from CENACARTA,Public, https://www.mozgis.gov.mz. D. Selected households from

$$
\text { Google Earth Pro }{ }^{\mathrm{TM}} \text {. }
$$

Figure 2. Malaria positive and negative cases in Sussundenga Village

Figire 3. Malaria prevalence by age group in Sussundenga Village, INE = National Institute of Statistics

460 


\section{Figures}

A

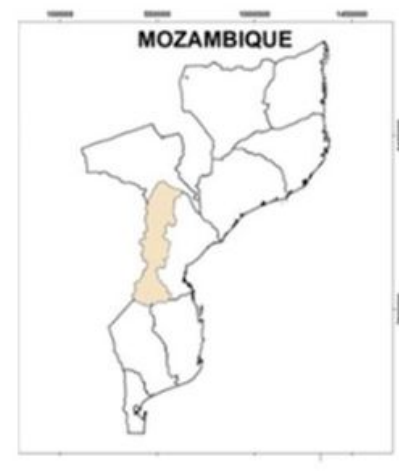

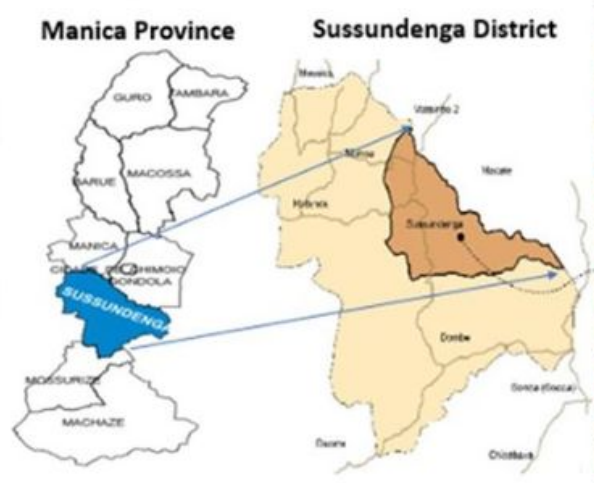
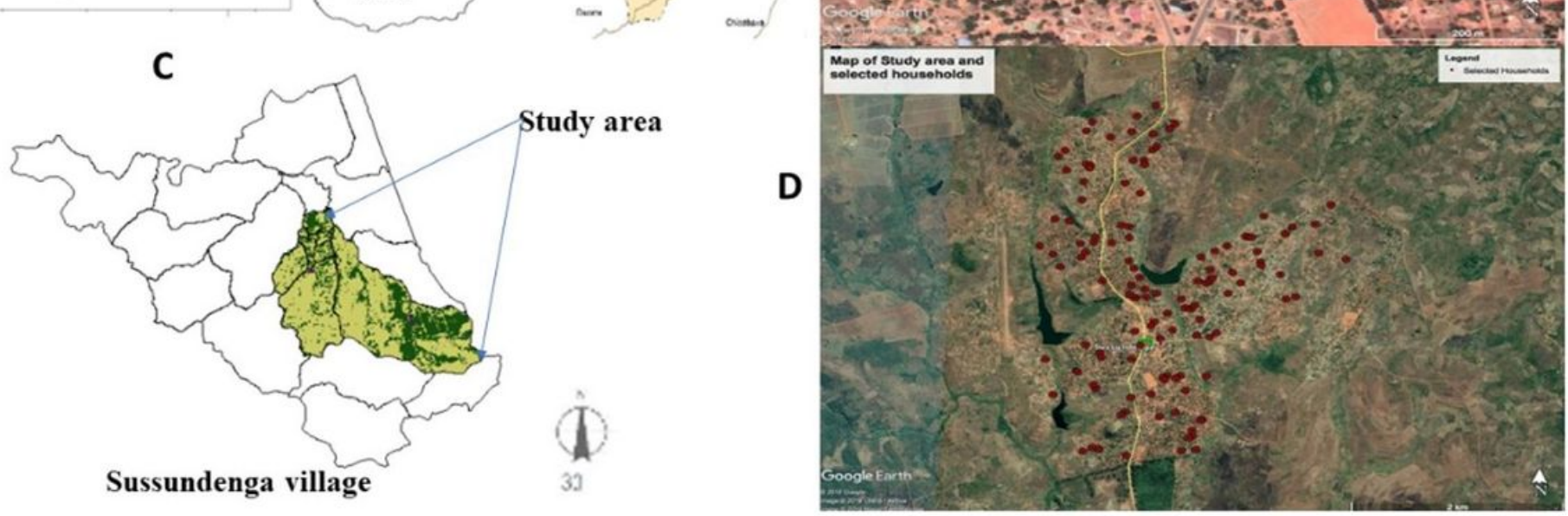

\section{Figure 1}

Study area. A. Map of Mozambique, Manica Province and Sussundenga District: adapted from CENACARTA, Public, https://www.mozgis.gov.mz. B. High resolution imagery of Sussundenga village from Google Earth ProTM C. Sampled site in Sussundenga Village: adapted from CENACARTA,Public, https://www.mozgis.gov.mz. D. Selected households from Google Earth ProTM. Note: The designations employed and the presentation of the material on this map do not imply the expression of any opinion whatsoever on the part of Research Square concerning the legal status of any country, territory, city or area or of its authorities, or concerning the delimitation of its frontiers or boundaries. This map has been provided by the authors. 


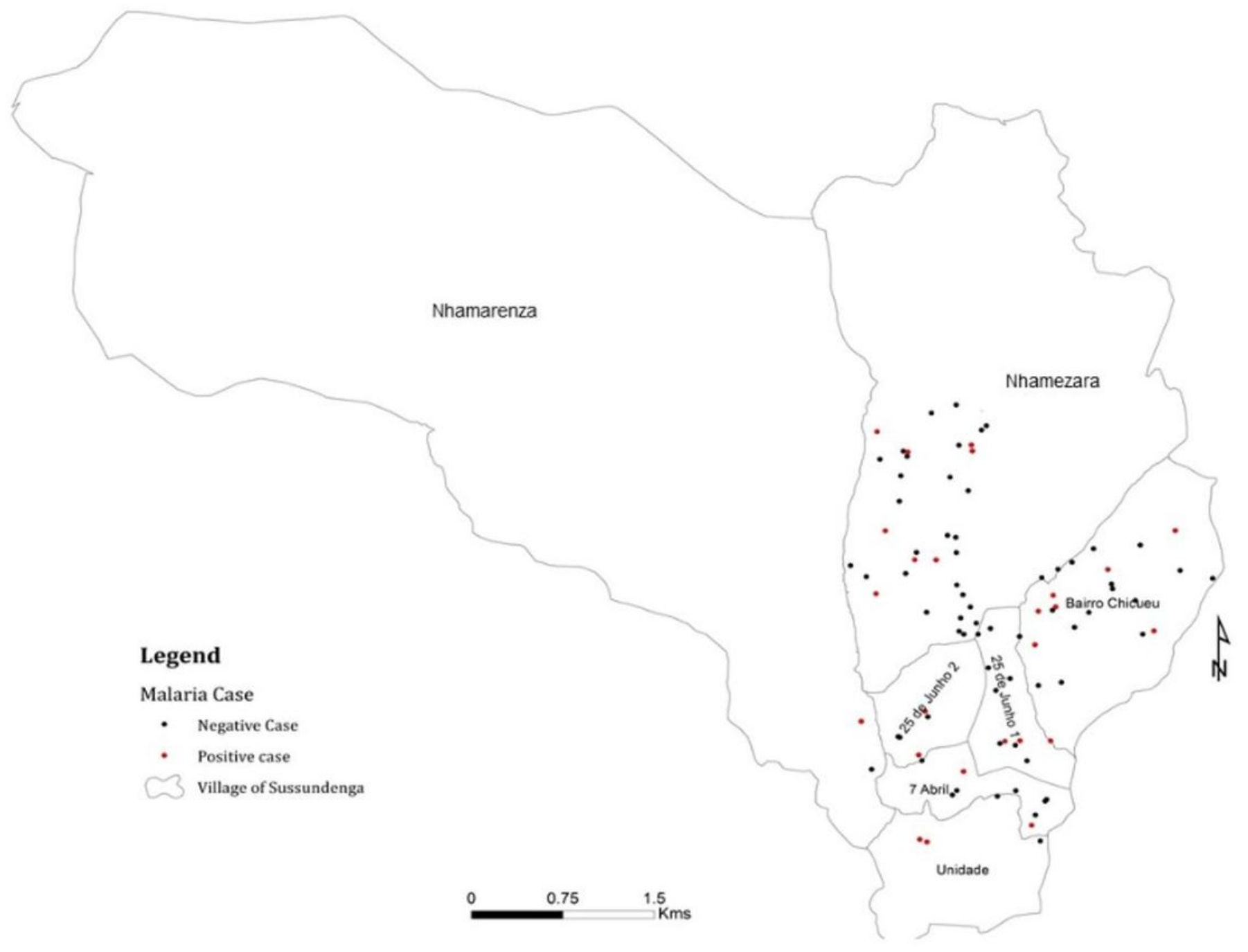

Figure 2

Malaria positive and negative cases in Sussundenga Village. Note: The designations employed and the presentation of the material on this map do not imply the expression of any opinion whatsoever on the part of Research Square concerning the legal status of any country, territory, city or area or of its authorities, or concerning the delimitation of its frontiers or boundaries. This map has been provided by the authors. 


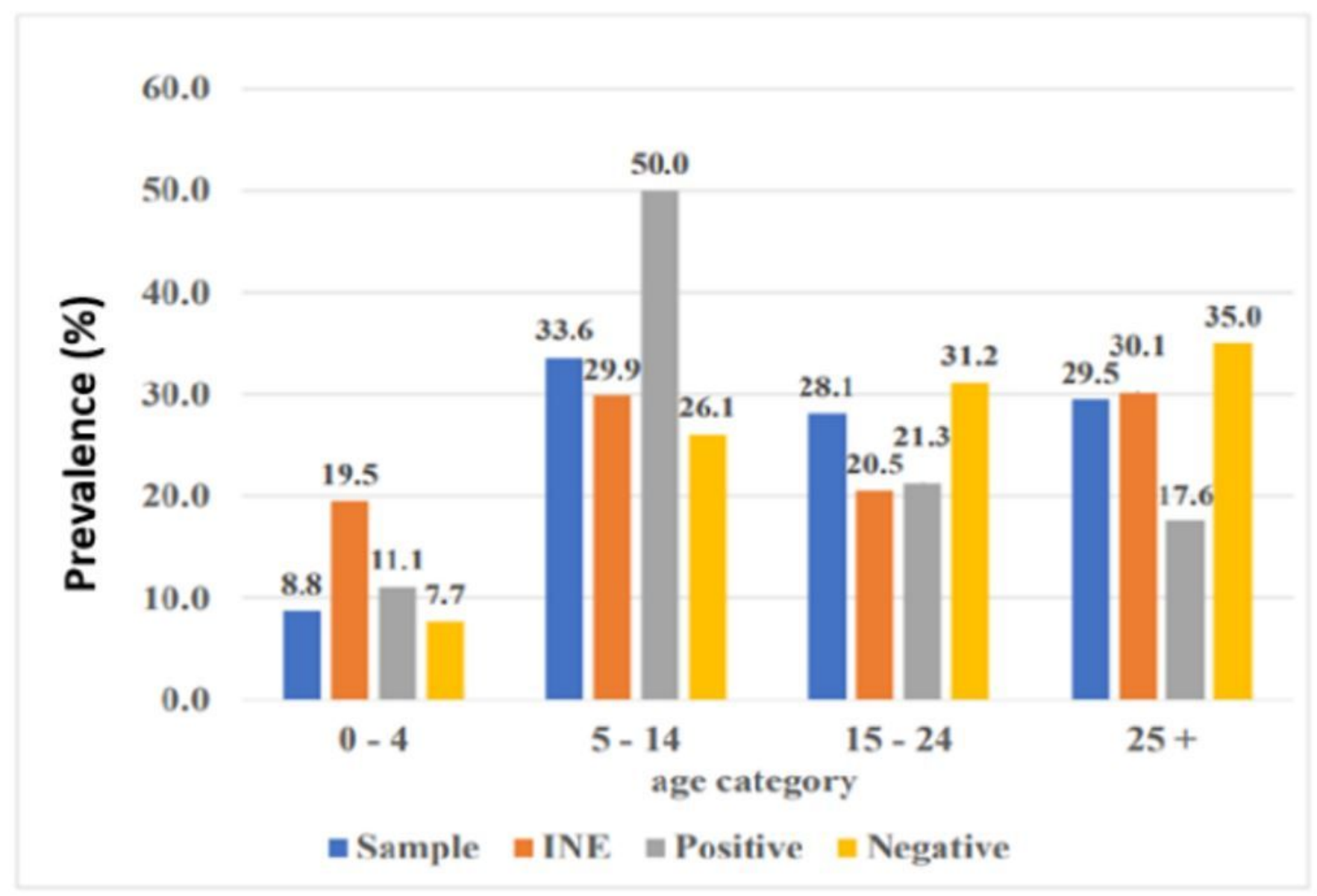

Figure 3

Malaria prevalence by age group in Sussundenga Village, INE = National Institute of Statistics

\section{Supplementary Files}

This is a list of supplementary files associated with this preprint. Click to download.

- Aditionalfile1.xIsx 